\title{
First Principles Approach to Extracting Chemical Information from X-Ray Absorption Near-Edge Spectra of Ga-Containing Materials
}

\author{
Kyle Groden, ${ }^{1, \dagger}$ Fernando D. Vila, $,{ }^{2, \dagger}, *$ Li Li,${ }^{3}$ Simon R. Bare, ${ }^{4}$ Susannah L. Scott, ${ }^{3,5, *}$ \\ and Jean-Sabin McEwen ${ }^{1,6,7,8,9, *}$
}

${ }^{1}$ The Gene and Linda Voiland School of Chemical Engineering and Bioengineering, Washington State University, Pullman, Washington 99164, United States

${ }^{2}$ Department of Physics, University of Washington, Seattle, Washington 98195, United States

${ }^{3}$ Department of Chemistry and Biochemistry, University of California, Santa Barbara, California 93106, United States

${ }^{4}$ Stanford Synchrotron Radiation Lightsource, SLAC National Accelerator Laboratory, Menlo Park, California 94025, United States

${ }^{5}$ Department of Chemical Engineering, University of California, Santa Barbara, California 93106, United States

${ }^{6}$ Institute for Integrated Catalysis, Pacific Northwest National Laboratory, Richland, Washington 99352, United States

${ }^{7}$ Department of Physics and Astronomy, Washington State University, Pullman, Washington 99164, United States

${ }^{8}$ Department of Chemistry, Washington State University, Pullman, Washington 99164, United States

${ }^{9}$ Department of Biological Systems Engineering, Washington State University, Pullman, Washington 99164, United States

*Corresponding authors: Fernando Vila (fdv@uw.edu), Susannah Scott (sscott@ucsb.edu) and Jean-Sabin McEwen (js.mcewen@wsu.edu)

†These authors contributed equally. 


\begin{abstract}
The X-ray absorption near edge structure (XANES) can provide uniquely detailed information on the coordination environments of important Ga-containing materials with unknown structures, including catalytically-active materials. In this study, the Ga K-edge XANES was simulated using first principles-based methods for seven molecular Ga complexes, as well $\beta-\mathrm{Ga}_{2} \mathrm{O}_{3}$, in order to explore the chemical origins of the experimentally observed features. The theoretical spectra were computed using FEFF, CASTEP and StoBE, in order to assess the sensitivity of the results to the computational approach. While the XANES features depend on the Ga coordination environment, they are also sensitive to the electronegativity of the ligands and the symmetry at Ga. The white line position responds to changes in both the core state (due to differential screening) and the valence " $p$ " states (arising from differences in ligand coordination).
\end{abstract}

\title{
Graphical TOC Entry
}

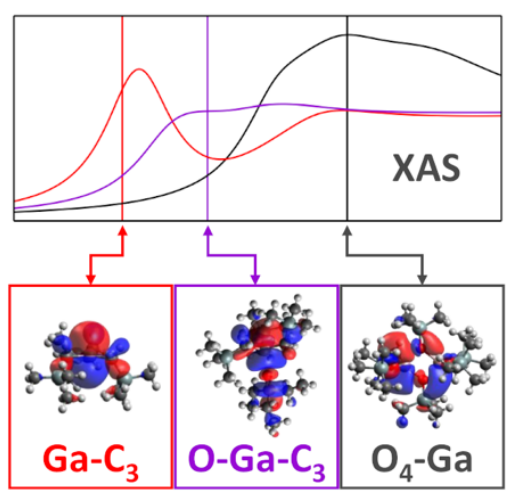




\section{Introduction}

Ga-based heterogeneous catalysts are interesting potential replacements for Pt- and Crbased catalysts in propane dehydrogenation, ${ }^{1}$ and are the basis for a commercial process for propane dehydroaromatization. ${ }^{2}$ Based on X-ray absorption spectra, IR spectra, and chemical titration evidence, as well as Density Functional Theory (DFT) modeling, the Ga sites proposed to be present in these materials under reaction conditions (typically, ca. $500{ }^{\circ} \mathrm{C}$ in the presence of $\mathrm{H}_{2}$ ) have been variously described as mononuclear $[\mathrm{Ga}]^{+},[\mathrm{GaO}]^{+},[\mathrm{GaH}(\mathrm{OH})]^{+},\left[\mathrm{Ga}(\mathrm{OH})_{2}\right]^{+},[\mathrm{GaH}]^{2+}$, and $\left[\mathrm{GaH}_{2}\right]^{+},{ }^{3-6}$ as well as dinuclear $\left[\mathrm{Ga}_{2} \mathrm{O}_{2}\right]^{2+}$ and $\left[\mathrm{Ga}_{2} \mathrm{O}_{2} \mathrm{H}_{2}\right]^{2+}{ }^{7-9}$ All are formally $\mathrm{Ga}(\mathrm{III})$, except for $[\mathrm{Ga}]^{+}$. Nevertheless, $\mathrm{Ga}(\mathrm{I})$ sites feature prominently in some proposed mechanisms for propane dehydrogenation, $3,5,10,11$ where their participation is a topic of on-going debate due to controversies about spectroscopic assignments.

In principle, X-ray absorption spectroscopy at the Ga K-edge can provide rich information about the local coordination and electronic structures of Ga sites, even at elevated reaction temperatures and in the presence of reactants. ${ }^{3,}{ }^{12-15}$ After calcination, supported Ga-containing catalysts have coordination numbers close to 4 with Ga-O distances ranging from 1.73 to $1.93 \AA$, , ${ }^{6,13}$ according to best-fit models of the EXAFS data. Activation in flowing $\mathrm{H}_{2}$ at $650{ }^{\circ} \mathrm{C}$ causes the amplitude of the Ga-O scattering path to decrease, implying that the active sites have a lower average coordination number, and/or that some of the oxygen-donor ligands have been replaced by hydrogen. ${ }^{4,13}$

Although the Ga K-edge XANES is sensitive to structural and electronic changes, rigorous XANES assignments remain challenging. The energies and intensities of the $1 s \rightarrow 4 p$ transitions which occur in the region of the absorption edge reflect both the Ga oxidation state and its local bonding geometry. After calcination, supported Ga catalysts show broad white line (WL) 
maxima in the range $10375-10380 \mathrm{eV}$, similar to $\mathrm{Ga}(\mathrm{III})$ standard materials such as $\beta-\mathrm{Ga}_{2} \mathrm{O}_{3}$ and $\mathrm{Ga}(\mathrm{acac})_{3} \cdot{ }^{13,16}$ Two peaks at the absorption edge have been assigned to tetrahedral and octahedral $\mathrm{Ga}(\mathrm{III})$ at photon energy values of 10375 and $10379 \mathrm{eV}$, respectively, and their intensities were used to estimate the fractions of each type of Ga site. ${ }^{17}$ During activation in flowing $\mathrm{H}_{2}$, the WL sharpens and shifts to lower energies $(10368-10373 \mathrm{eV}){ }^{3,4,6,10}$ In early studies, this shift was attributed to the reduction of $\mathrm{Ga}(\mathrm{III})$ to $\mathrm{Ga}(\mathrm{I}),{ }^{3}$ by comparison to the energy of a peak assigned to the $\mathrm{Ga}(\mathrm{I})$ component in mixed-valent $\mathrm{Ga}_{2} \mathrm{Cl}_{4}$ (i.e., $\left.\mathrm{Ga}(\mathrm{I}) \mathrm{Ga}(\mathrm{III}) \mathrm{Cl}_{4}\right) .{ }^{10}$ However, this assignment was subsequently questioned in a XANES study of well-defined molecular Ga(III) complexes, ${ }^{16}$ whose edge positions cover the full range of energies assigned. In particular, the WL of trigonal planar $\mathrm{Ga}\left(\mathrm{CH}_{2} \mathrm{SiMe}_{3}\right)_{3}$ appears at ca. $10371 \mathrm{eV}$, compared to $10370 \mathrm{eV}$ for the $\mathrm{Ga}(\mathrm{I})$ site in $\mathrm{Ga}_{2} \mathrm{Cl}_{4}$. Thus, changes in the nature of the ligands and/or the Ga coordination number can cause the edge position to shift as much as a reduction in the formal oxidation state, with implications for the identification of active sites and reaction mechanisms in heterogeneous Ga catalysts.

To understand the fundamental causes of these dramatic differences, we undertook a study of variations in the Ga K-edge XANES for a series of six well-defined Ga(III) compounds, namely, $\left[\mathrm{Ga}\left(\mathrm{OSiPh}_{3}\right)_{3}\right]_{2}, \quad\left[\mathrm{Ga}\left(\mathrm{CH}_{2} \mathrm{SiMe}_{3}\right)\left(\mathrm{OSiPh}_{3}\right)_{2}\right]_{2}, \quad\left[\mathrm{Ga}\left(\mathrm{CH}_{2} \mathrm{SiMe}_{3}\right)_{2}\left(\mathrm{OSiPh}_{3}\right)\right]_{2}, \quad \mathrm{Ga}\left(\mathrm{CH}_{2} \mathrm{SiMe}_{3}\right)_{3}$, $\mathrm{Ga}\left(\mathrm{CH}_{2} \mathrm{SiMe}_{3}\right)_{3}\left(\mathrm{OP}(n-\mathrm{Bu})_{3}\right)$ and $\mathrm{Ga}(t-\mathrm{Bu})_{2}\left(\mathrm{OC}_{6} \mathrm{H}_{2}-2,4,6,-t-\mathrm{Bu}_{3}\right)$, as well as for $\beta-\mathrm{Ga}_{2} \mathrm{O}_{3}$, a reference material often used in XANES studies of Ga(III). Clearly, the widely differing appearances of the experimental spectra for the molecular complexes (shown in Figure 1 and originally reported by Getsoian et al. $)^{16}$ are not a consequence solely of Ga oxidation state, which is formally (III) in all of the complexes, but also of their coordination environments. For this study, we performed simulations of the Ga K-edge XANES for each molecular complex using three firstprinciples methods: FEFF, ${ }^{18,}{ }^{19} \mathrm{CASTEP},{ }^{20}$ and StoBe. ${ }^{21}$ The results reveal the origins of the 
differences in the electronic structures of the Ga(III) compounds, and have implications on the interpretation of XANES characterization measurements for Ga-based catalysts.

\section{Methods}

CASTEP Simulations. Quantum mechanical optimizations of all molecular structures (as depicted in Figures S1-S7) were performed with the CASTEP code, ${ }^{22}$ using the PBE functional. Ga K-edge X-ray absorption near-edge structure (XANES) spectra were simulated by generating a Ga pseudopotential with a $1 s$ core hole, and performing a regular SCF cycle to generate the Kohn-Sham states (occupied and unoccupied) under the influence of the core hole. ${ }^{20}$ The valence electron Kohn-Sham states were expanded using a series of plane waves, with a cutoff energy of at least $570 \mathrm{eV}$. Core electrons were treated using ultrasoft pseudopotentials, generated using allelectron atomic calculations prior to the beginning of standard self-consistent field cycles. ${ }^{22}$ Electronic exchange and correlation were computed within the generalized gradient approximation using the Perdew-Burke-Erzenhof (PBE) functional. ${ }^{23}$ For calculations involving isolated molecules, the reciprocal space was sampled using only the $\Gamma$ point. Prior to electronic structure analysis, molecular geometries were optimized until all atomic forces were less than $0.03 \mathrm{eV} / \AA$. For calculations involving $\beta$ - $\mathrm{Ga}_{2} \mathrm{O}_{3}{ }^{24}$, the RPBE functional was used with an optimized volume of $1357 \AA^{3}\left(a=12.63 \AA, b=9.32 \AA, c=11.85 \AA, \alpha=90.0^{\circ}, \beta=103.7^{\circ}, \gamma=90.0^{\circ}\right)$. We note that the unit cell used here was a $1 \times 2 \times 3$ unit cell to avoid artifacts in the computed XANES spectra due to the imposed periodic boundary conditions. The optimized geometries for the molecular complexes and the bulk oxide structure are provided as supplementary information in CIF format. A $k$-point grid $(4 \times 5 \times 6)$ was used to calculate the XANES of $\beta-\mathrm{Ga}_{2} \mathrm{O}_{3}$. In order to enable 
quantitative comparison of StoBE and FEFF results, the XANES spectra of some complexes and $\beta-\mathrm{Ga}_{2} \mathrm{O}_{3}$ were calculated using simplified and/or truncated geometries.

Absorption spectra were computed by evaluating the dipole transition matrix elements between the $1 s$ core state and unoccupied Kohn-Sham states. The computed XANES were broadened using Gaussian functions with a full-width at half-maximum (FWHM) of $0.6 \mathrm{eV}$ to simulate machine broadening as well as the default Ga lifetime broadening factors implemented in the Materials Studio package ${ }^{25}$. For comparison with experiment, each simulated spectrum (which was computed on an energy scale referenced to the Fermi energy) was shifted to align its first maximum with the corresponding peak in the experimental spectrum. More details are given in the Supporting Information.

StoBe and FEFF Simulations. The same molecular structures of Ga(III) complexes (obtained from PBE optimizations using CASTEP) were used in both the StoBe $2011^{21}$ and FEFF 9.6 $6^{18,19}$ simulations. For $\beta$ - $\mathrm{Ga}_{2} \mathrm{O}_{3}$, FEFF simulations were performed with clusters of radii 5.0 and 9.0 $\AA$ for the SCF and FMS, respectively, to obtain converged results. All other FEFF settings were defaults. For comparison to the published experimental data, the FEFF simulations were broadened using default parameters.

Since $\mathrm{StoBe}$ is a molecular code, its use to simulate the spectrum of crystalline $\beta-\mathrm{Ga}_{2} \mathrm{O}_{3}$ required the use of clusters (Figures S8 and S9). These were generated from the same experimental structure $^{26}$ in order to represent the tetrahedral and octahedral Ga sites consistently. For the StoBe simulations, the core-excited Ga atom was described using the all-electron IGLO F-III basis set. For other atoms, the basis sets and associated effective core potentials for $\mathrm{Ga}(+13)(51 / 41 / 41)$, $\mathrm{Si}(+4)(311 / 211 / 1), \mathrm{P}(+5)(311 / 211 / 1), \mathrm{O}(+6)(321 / 311 / 1), \mathrm{C}(+4)(321 / 311 / 1)$, and H (311/1) (as distributed in StoBe) were used. Finally, StoBe simulations were performed using PBE, RPBE or 
B88PD86 exchange-correlation functionals. ${ }^{27,28}$ The StoBe simulations were broadened using an ad hoc self-energy with constant real and variable imaginary parts, as described previously. ${ }^{29}$

X-ray Absorption Spectroscopy. The XAS spectrum of $\beta-\mathrm{Ga}_{2} \mathrm{O}_{3}$ was recorded at the $\mathrm{Ga} \mathrm{K}$ edge $(10,367 \mathrm{eV})$ on beamline $2-2, \operatorname{Si}(111) \phi=90^{\circ}$, at the Stanford Synchrotron Radiation Lightsource, which operates at $3.0 \mathrm{GeV}$ with a current of $500 \mathrm{~mA} . \beta-\mathrm{Ga}_{2} \mathrm{O}_{3}(99.99 \%$, SigmaAldrich) was diluted to ca. 2 wt $\%$ Ga with BN (99.5 \%, Alfa Aesar). $\mathrm{GaMe}_{3}$ (Strem, 99\%) was diluted to ca. $2 \mathrm{wt} \% \mathrm{Ga}$ with n-pentane (Acros Organics, 99\%). Data were acquired in transmission mode, using $\mathrm{N}_{2}$-filled ionization chambers as detectors. For energy calibration, a W foil ( $\mathrm{L}_{\mathrm{III}}$-edge, $10,207 \mathrm{eV}$ ) was placed after the second ionization chamber following the incident beam direction. Experimental XAS data were processed and analyzed using the Demeter software package. ${ }^{30} \mathrm{~A}$ linear function was subtracted from the pre-edge region, then the edge jump was normalized using the Athena program. The $\chi(k)$ data were isolated by subtracting a smooth, third-order polynomial approximating the absorption background of an isolated atom. 


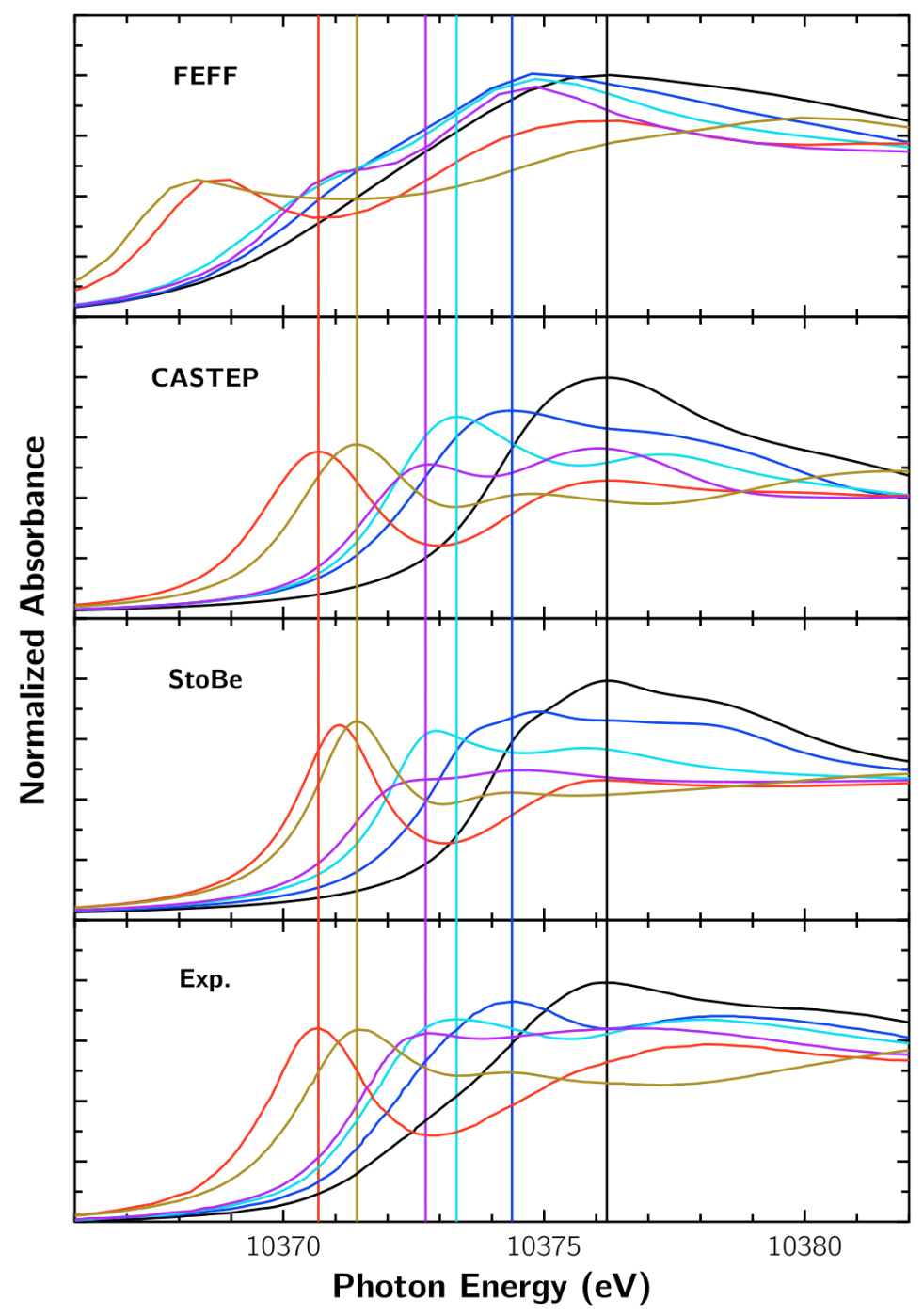

$\left[\mathrm{Ga}\left(\mathrm{OSiPh}_{3}\right)_{3}\right]_{2}$ $\left[\mathrm{Ga}\left(\mathrm{CH}_{2} \mathrm{SiMe}_{3}\right)\left(\mathrm{OSiPh}_{3}\right)_{2}\right]_{2}$ $\left[\mathrm{Ga}\left(\mathrm{CH}_{2} \mathrm{SiMe}_{3}\right)_{2}\left(\mathrm{OSiPh}_{3}\right)\right]_{2}$
$\mathrm{Ga}\left(\mathrm{CH}_{2} \mathrm{SiMe}_{3}\right)_{3}$ $\mathrm{Ga}\left(\mathrm{CH}_{2} \mathrm{SiMe}_{3}\right)_{3}\left(\mathrm{OP}(n-\mathrm{Bu})_{3}\right)$ $\mathrm{Ga}(t-\mathrm{Bu})_{2}\left(\mathrm{OC}_{6} \mathrm{H}_{2}-2,4,6,-t-\mathrm{Bu}_{3}\right)$

Figure 1: Comparison of published ${ }^{16}$ experimental XANES for six molecular Ga complexes, with simulations obtained using three theoretical approaches. The vertical lines indicate the position of the first maximum in the experimental XANES for each complex. Each CASTEP simulation was individually shifted to align with these experimental peaks. Spectra simulated using either FEFF and StoBE were shifted by a common amount, based on the shift required to match the experimental maximum for $\left[\mathrm{Ga}\left(\mathrm{OSiPh}_{3}\right)_{3}\right]_{2}$ (black vertical line). 


\section{Results and Discussion}

The experimental and theoretical XANES spectra for six molecular Ga(III) compounds are compared in Figure 1. Since CASTEP does not provide an absolute energy scale, each CASTEP spectrum was adjusted so that its first maximum is aligned with the experimental value. The absolute positions of the CASTEP spectra can be obtained from first principles using the method of Pickard and coworkers ${ }^{31}$ (see Figure S10). In contrast, the FEFF and StoBe spectra require only an overall energy shift, therefore the maximum in the simulated spectrum of $\left[\mathrm{Ga}\left(\mathrm{OSiPh}_{3}\right)_{3}\right]_{2}$ was aligned with the experimental value, and all other simulations performed using the same method were shifted by the same amount. The overall agreement between theory and experiment is striking for both the StoBe and CASTEP simulations. In particular, StoBe provides very good estimates for the relative positions of the first maxima in each complex and reproduces the overall shape of the spectra. The latter is also true for CASTEP. The agreement is less good for the FEFF results. The large differences between the FEFF simulations and the experimental spectra arise from the muffin-tin approximation. ${ }^{32}$ It is particularly ill-suited for some of these molecular Ga complexes, due to the large local anisotropies in their electronic structures. Nevertheless, FEFF does provide much better agreement when the local environment is more isotropic, as discussed below for $\beta-\mathrm{Ga}_{2} \mathrm{O}_{3}$.

The most noticeable differences between theory and experiment occur $8-10 \mathrm{eV}$ above the edge. In this region, the CASTEP simulations resemble the experimental results better, likely due to CASTEP's use of plane waves, vs. the local Gaussian-type orbitals (GTOs) used by StoBe, which capture long-range behavior more accurately than a localized basis set. In principle, the accuracy of the simulations may also be affected by the choice of exchange-correlation functional, 
and the quality of the structural models. However, Figure 2 shows that the XANES simulations are largely insensitive to the choice of functional (see also Figures S11-S13). In addition, they are relatively insensitive to geometry simplifications distant from the Ga absorber: there was little change when the phenyl substituents located ca. $4 \AA$ distant from Ga were replaced by methyls (Figure S14).

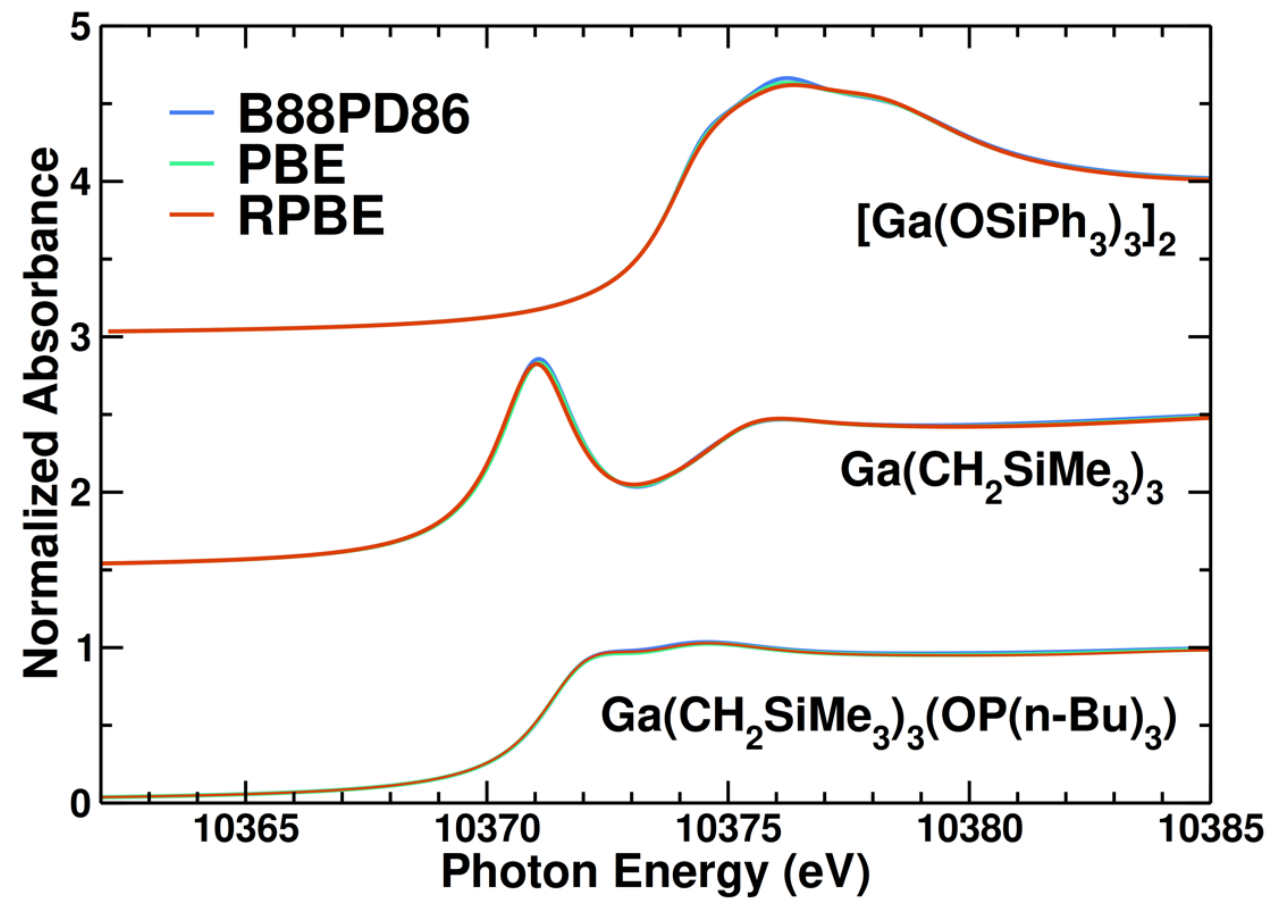

Figure 2: Comparison of the StoBe-predicted XANES for three representative molecular Ga complexes using the B88PD86, PBE and RPBE exchange-correlation functionals. The spectra were shifted as in Figure 1, based on the shift required to match the experimental maximum for $\left[\mathrm{Ga}\left(\mathrm{OSiPh}_{3}\right)_{3}\right]_{2}$. 
Table 1: Relative white line energies (WLE) predicted by StoBe for various molecular Ga(III) complexes and $\beta$ - $\mathrm{Ga}_{2} \mathrm{O}_{3}$ with differing local $\mathrm{Ga}$ coordination environments, and the contributions to WLE of the core ionization energy (CIE) and valence state energy (VSE) ${ }^{\mathrm{a}}$

\begin{tabular}{|c|c|c|c|c|c|c|}
\hline Molecular Ga complex & $\begin{array}{l}\text { Coordination } \\
\text { environment }\end{array}$ & WLE & CIE & VSE & $\begin{array}{c}\text { Valence } \\
\text { occupancy }^{b}\end{array}$ & $d(\mathrm{Ga}-\mathrm{L})^{\mathrm{c}}$ \\
\hline$\beta-\mathrm{Ga}_{2} \mathrm{O}_{3}$ (oct) & $\mathrm{O}_{6}-\mathrm{Ga}$ & 3.01 & 2.50 & 0.51 & 1.21 & 1.93 \\
\hline$\beta-\mathrm{Ga}_{2} \mathrm{O}_{3}($ tet $)$ & $\mathrm{O}_{4}-\mathrm{Ga}$ & 0.58 & 2.71 & -2.13 & 1.20 & 1.83 \\
\hline$\left[\mathrm{Ga}\left(\mathrm{OSiPh}_{3}\right)_{3}\right]_{2}$ & $\mathrm{O}_{4}-\mathrm{Ga}$ & -2.49 & 0.00 & -2.49 & 1.07 & 1.79 \\
\hline$\left[\mathrm{Ga}\left(\mathrm{CH}_{2} \mathrm{SiMe}_{3}\right)\left(\mathrm{OSiPh}_{3}\right)_{2}\right]_{2}$ & $\mathrm{O}_{3}-\mathrm{Ga}-\mathrm{C}$ & -3.46 & -0.82 & -2.64 & 1.14 & 1.84 \\
\hline$\left[\mathrm{Ga}\left(\mathrm{CH}_{2} \mathrm{SiMe}_{3}\right)_{2}\left(\mathrm{OSiPh}_{3}\right)\right]_{2}$ & $\mathrm{O}_{2}-\mathrm{Ga}-\mathrm{C}_{2}$ & -4.25 & -1.47 & -2.78 & 1.20 & 1.98 \\
\hline $\mathrm{Ga}\left(\mathrm{CH}_{2} \mathrm{SiMe}_{3}\right)_{3}\left(\mathrm{OP}(n-\mathrm{Bu})_{3}\right)$ & $\mathrm{O}-\mathrm{Ga}-\mathrm{C}_{3}$ & -5.08 & -2.75 & -2.33 & 1.30 & 2.01 \\
\hline $\mathrm{Ga}(t-\mathrm{Bu})_{2}\left(\mathrm{OC}_{6} \mathrm{H}_{2}-2,4,6-t-\mathrm{Bu}_{3}\right)$ & $\mathrm{O}-\mathrm{Ga}-\mathrm{C}_{2}$ & -5.53 & -1.31 & -4.22 & 1.18 & 1.85 \\
\hline $\mathrm{Ga}\left(\mathrm{CH}_{2} \mathrm{SiMe}_{3}\right)_{3}$ & $\mathrm{Ga}-\mathrm{C}_{3}$ & -5.85 & -1.57 & -4.28 & 1.28 & 1.99 \\
\hline $\mathrm{GaMe}_{3}$ & $\mathrm{Ga}-\mathrm{C}_{3}$ & -5.98 & -1.05 & -4.93 & 1.40 & 1.98 \\
\hline
\end{tabular}

$\overline{{ }^{a}}$ All energies are in $\mathrm{eV}$, and are reported relative to the $\mathrm{CIE}$ of $\left[\mathrm{Ga}\left(\mathrm{OSiPh}_{3}\right)_{3}\right]_{2} \cdot{ }^{\mathrm{b}}$ Total $\mathrm{Ga}$ valence (sp) occupancy, from Natural Atomic Orbital analysis. ${ }^{\mathrm{c} M i n i m u m ~ d i s t a n c e ~(i n ~} \AA$ ) between Ga and its near-neighbor atoms.

Table 1 shows the WL energy (WLE) predicted by StoBe for each complex, as well as values for the core ionization energy (CIE) and the energy of the first excited valence state (VSE), where WLE $=$ CIE + VSE. All energies are given relative to the highest CIE, found for $\left[\mathrm{Ga}\left(\mathrm{OSiPh}_{3}\right)_{3}\right]_{2}$. The 3 -coordinate complexes $\mathrm{Ga}\left(\mathrm{CH}_{2} \mathrm{SiMe}_{3}\right)_{3}$ and $\mathrm{Ga}(t-\mathrm{Bu})_{2}\left(\mathrm{OC}_{6} \mathrm{H}_{2}-2,4,6,-t-\mathrm{Bu}_{3}\right.$, as well as $\mathrm{GaMe}_{3}$ (see Figure S15), have lower WLEs than any of the 4-coordinate complexes 
$\left[\mathrm{Ga}\left(\mathrm{OSiPh}_{3}\right)_{3}\right]_{2}, \quad\left[\mathrm{Ga}\left(\mathrm{CH}_{2} \mathrm{SiMe}_{3}\right)\left(\mathrm{OSiPh}_{3}\right)_{2}\right]_{2}, \quad\left[\mathrm{Ga}\left(\mathrm{CH}_{2} \mathrm{SiMe}_{3}\right)_{2}\left(\mathrm{OSiPh}_{3}\right)\right]_{2} \quad$ and $\mathrm{Ga}\left(\mathrm{CH}_{2} \mathrm{SiMe}_{3}\right)_{3}\left(\mathrm{OP}(n-\mathrm{Bu})_{3}\right)$. A similar dependence of the WLE on coordination number was reported for the $\mathrm{K}$-edges of $\mathrm{Cu}(\mathrm{II}), \mathrm{Zn}(\mathrm{II}), \mathrm{Al}(\mathrm{III})$, and $\mathrm{Ti}(\mathrm{IV})$ complexes. ${ }^{33-37}$ In the series of $\mathrm{Ga}$ compounds, the shift in WLE is associated mainly with a change in the position of the first intense transition, with the 3-coordinate compounds showing larger negative average VSE values $(-4.5 \pm$ $0.4 \mathrm{eV})$ compared to the 4-coordinate compounds $(-2.5 \pm 0.2 \mathrm{eV})$.

To understand the origin of the coordination number dependence of the WLE, molecular orbitals associated with the first intense transition were computed, and are shown in Figure 3 for three representative cases: 3-coordinate $\mathrm{Ga}\left(\mathrm{CH}_{2} \mathrm{SiMe}_{3}\right)_{3}$, 4-coordinate $\left[\mathrm{Ga}\left(\mathrm{OSiPh}_{3}\right)_{3}\right]_{2}$, and intermediate $\mathrm{Ga}\left(\mathrm{CH}_{2} \mathrm{SiMe}_{3}\right)_{3}\left(\mathrm{OP}(n-\mathrm{Bu})_{3}\right)$, which is a 4-coordinate complex but with a Ga- $\mathrm{C}_{3}$ moiety that is nearly planar. Since the XANES is closely associated with the final state wavefunction, ${ }^{38}$ the orbitals calculated by either CASTEP or StoBe for the bound excited valence states associated with the WL are quite similar, despite being calculated using plane waves and GTOs, respectively. The main difference is that the CASTEP orbitals appear to be slightly more delocalized. Orbitals associated with higher energy transitions also have greater spatial extension (Figures S16-S18). However, WLEs are unlikely to be greatly affected by delocalization of bound states, since the dipole matrix elements are determined mainly by contributions from the local environment around the Ga absorber. 


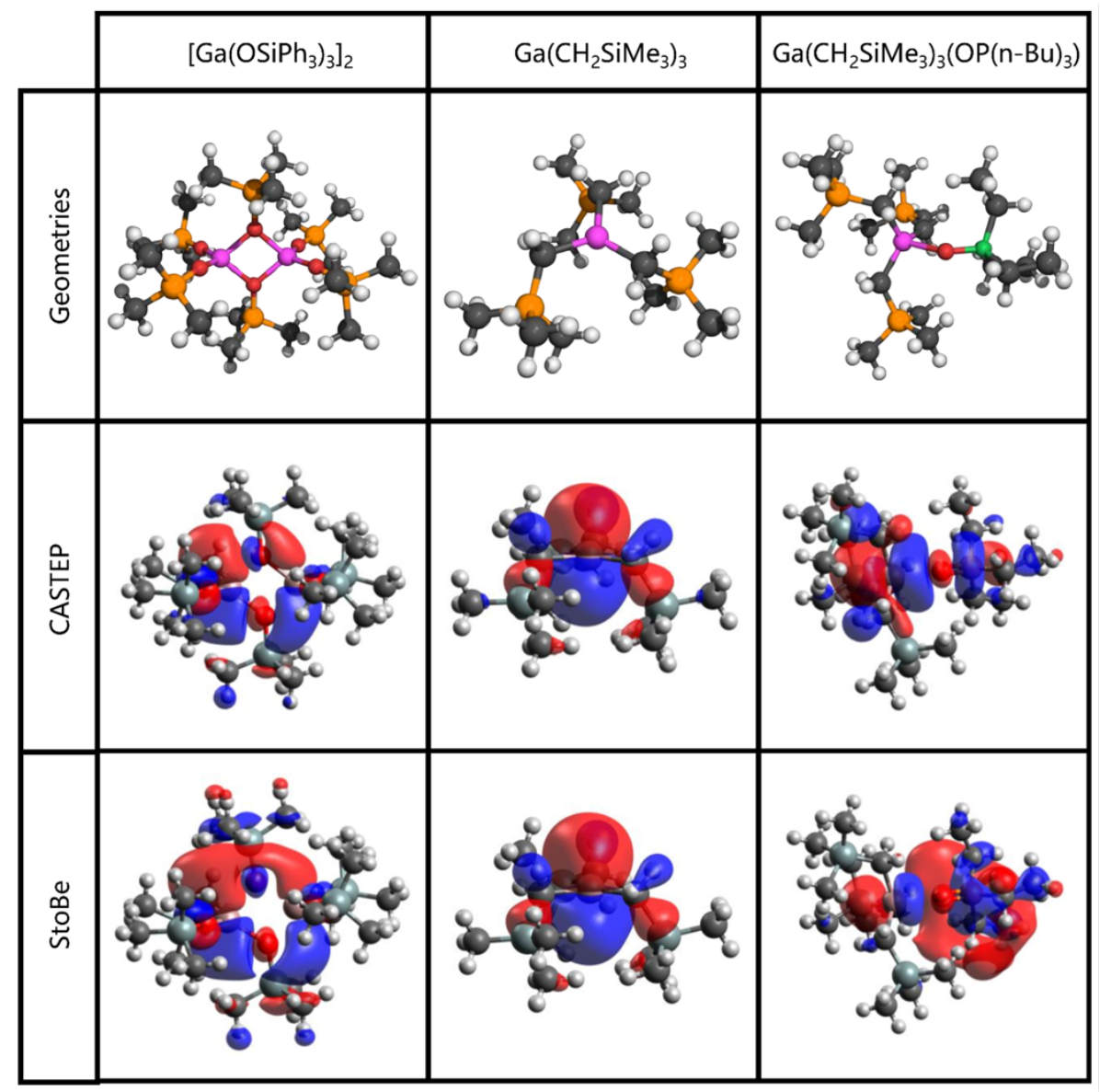

Figure 3: Comparison of CASTEP optimized geometries for three representative Ga complexes and the molecular orbitals calculated by CASTEP and StoBe for the excited states associated with their white lines. Color scheme for geometries in top panels: Ga (pink), Si (orange), C (grey), H (white), O (red), P (green). Color scheme for orbitals: Ga (pink), Si (light grey), C (grey), H (white), O (red), P (orange). The orbitals are represented at an isosurface value of $0.02 \mathrm{Bohr}^{-3 / 2}$.

Given the dipole selection rules for K-edges, it is not surprising that all the calculated orbitals have considerable Ga $p$-character. The orbital at the WLE associated with 3-coordinate $\mathrm{Ga}\left(\mathrm{CH}_{2} \mathrm{SiMe}_{3}\right)_{3}$ is almost "pure" $p$, due to the trigonal planar nature of the Ga- $\mathrm{C}_{3}$ arrangement. In contrast, the corresponding orbital associated with 4-coordinate, non-planar $\left[\mathrm{Ga}\left(\mathrm{OSiPh}_{3}\right)_{3}\right]_{2}$ 
includes an antibonding component that reflects coupling to ligand-based orbitals. This difference explains much of the coordination-number dependent VSE shift of ca. $2.0 \mathrm{eV}$ in the associated transitions: relative to the energy of the $p$ orbital in the 3-coordinate complex, anti-bonding coupling to the ligand orbitals raises the state energy in the 4-coordinate complex, resulting in an increased transition energy that is closer to the ionization energy. The VSE in $\mathrm{Ga}\left(\mathrm{CH}_{2} \mathrm{SiMe}_{3}\right)_{3}\left(\mathrm{OP}(n-\mathrm{Bu})_{3}\right)$ is intermediate since, similar to 3 -coordinate $\mathrm{Ga}\left(\mathrm{CH}_{2} \mathrm{SiMe}_{3}\right)_{3}$, its orbital has well-defined $p$-character, yet the presence of some antibonding coupling involving the $\mathrm{OP}(n-\mathrm{Bu})_{3}$ ligand still increases the transition energy as in 4-coordinate $\left[\mathrm{Ga}\left(\mathrm{OSiPh}_{3}\right)_{3}\right]_{2}$.

As Table 1 shows, the minimum distance and its nearest neighbor atoms varies with the electronegativity of the ligand, from $1.79 \AA$ for $\mathrm{O}_{4}-\mathrm{Ga}$ to $2.01 \AA$ for $\mathrm{O}-\mathrm{Ga}_{-} \mathrm{C}_{3}$, with a corresponding shift of $2.6 \mathrm{eV}$ in the WLEs. This effect is manifested in the CIE, where the difference between the highest and lowest CIEs (for $\left[\mathrm{Ga}\left(\mathrm{OSiPh}_{3}\right)_{3}\right]_{2}$ and $\mathrm{Ga}\left(\mathrm{CH}_{2} \mathrm{SiMe}_{3}\right)_{3}\left(\mathrm{OP}(n-\mathrm{Bu})_{3}\right)$, respectively) is $2.8 \mathrm{eV}$ (Table 1). The effect is therefore larger than the $2.0 \mathrm{eV}$ change in VSE which results from the increase in coordination number from 3 to 4 , and more gradual. The change in CIE correlates with the overall valence occupation of Ga, estimated using Natural Atomic Orbital analysis, ${ }^{39}$ which is in turn related to the average nearest-neighbor distance. Longer bond distances result in more localized Ga valence states and larger valence occupations, which screen the core states more efficiently. However, the CIE also depends, to a lesser degree, on the second coordination sphere of the complex, since both $\mathrm{Ga}\left(\mathrm{CH}_{2} \mathrm{SiMe}_{3}\right)_{3}$ and $\mathrm{GaMe}_{3}$ have the same $\mathrm{Ga}-\mathrm{C}_{3}$ nearest neighbor environment, while their CIE values differ by $-0.52 \mathrm{eV}$ (with the $\mathrm{CIE}$ value for $\mathrm{Ga}\left(\mathrm{CH}_{2} \mathrm{SiMe}_{3}\right)_{3}$ being more negative than for $\mathrm{GaMe}_{3}$ ). The $\mathrm{CIE}$ also likely reflects the difference between a methyl and a neosilyl due to the hyperconjugation involving the Si atom, which alters the electron density at the carbon donor atom. 
We also explored the XANES of $\beta-\mathrm{Ga}_{2} \mathrm{O}_{3}$, a common reference material used in spectroscopy of Ga-containing heterogeneous catalysts. This oxide contains both tetrahedral and octahedral Ga sites. Figure 4 shows the experimental spectrum as well as FEFF, CASTEP and StoBe simulations of the $\beta$ - $\mathrm{Ga}_{2} \mathrm{O}_{3}$ XANES, including the contributions from each Ga site and their average (where the latter is used for quantitative comparison between theory and experiment). The WL appears at an even higher energy than for 4-coordinate $\left[\mathrm{Ga}\left(\mathrm{OSiPh}_{3}\right)_{3}\right]_{2}$, the most closelyrelated of the $\mathrm{Ga}(\mathrm{III})$ molecular systems (10380 vs. $10376 \mathrm{eV}$, respectively). The agreement between the calculated spectra and the experimental data is particularly good for the FEFF and StoBe calculations.

Surprisingly, all three theoretical methods find that the main peak associated with the 6coordinate site in $\beta-\mathrm{Ga}_{2} \mathrm{O}_{3}$ appears at a lower energy than that for the 4-coordinate site. This order seems counterintuitive, given that higher coordination numbers in the molecular Ga complexes described above are correlated with higher WLEs. However, both FEFF and StoBe predict a lower energy shoulder for the 4-coordinate site, which is absent in the contribution from the 6-coordinate site. The shoulder is clearly visible in the experimental spectrum at ca. $10377 \mathrm{eV}$, just before the WL. Thus, the lowest energy feature for the 4-coordinate site does indeed precede the main peak for the 6-coordinate site. To further deconvolute the XANES dependence on the Ga coordination number, we compare the $\mathrm{VSE}$ value of $\left[\mathrm{Ga}\left(\mathrm{OSiPh}_{3}\right)_{3}\right]_{2},-2.49 \mathrm{eV}$, with that of the 4-coordinate site of $\beta-\mathrm{Ga}_{2} \mathrm{O}_{3},-2.13 \mathrm{eV}$ (Table 1). The small difference is likely due to symmetry: $\mathrm{Ga}$ in $\left[\mathrm{Ga}\left(\mathrm{OSiPh}_{3}\right)_{3}\right]_{2}$ is distorted from tetrahedrality relative to the nearly perfect tetrahedral environment in the oxide. Compared to $\left[\mathrm{Ga}\left(\mathrm{OSiPh}_{3}\right)_{3}\right]_{2}$, the higher WLE value for the 4-coordinate site in $\beta-\mathrm{Ga}_{2} \mathrm{O}_{3}$ (resulting in the main peak) is due to its positive CIE value. We hypothesize that it reflects the withdrawing effect of oxygen in higher coordination shells on the Ga electron density, 
as well as the difference in symmetry. Finally, we note that the VSE value for the 6-coordinate site in $\beta-\mathrm{Ga}_{2} \mathrm{O}_{3}$ correlates well with its coordination environment, since its positive value of 0.51 $\mathrm{eV}$ is larger than for any other complex in Table 1, all of which have lower coordination numbers.

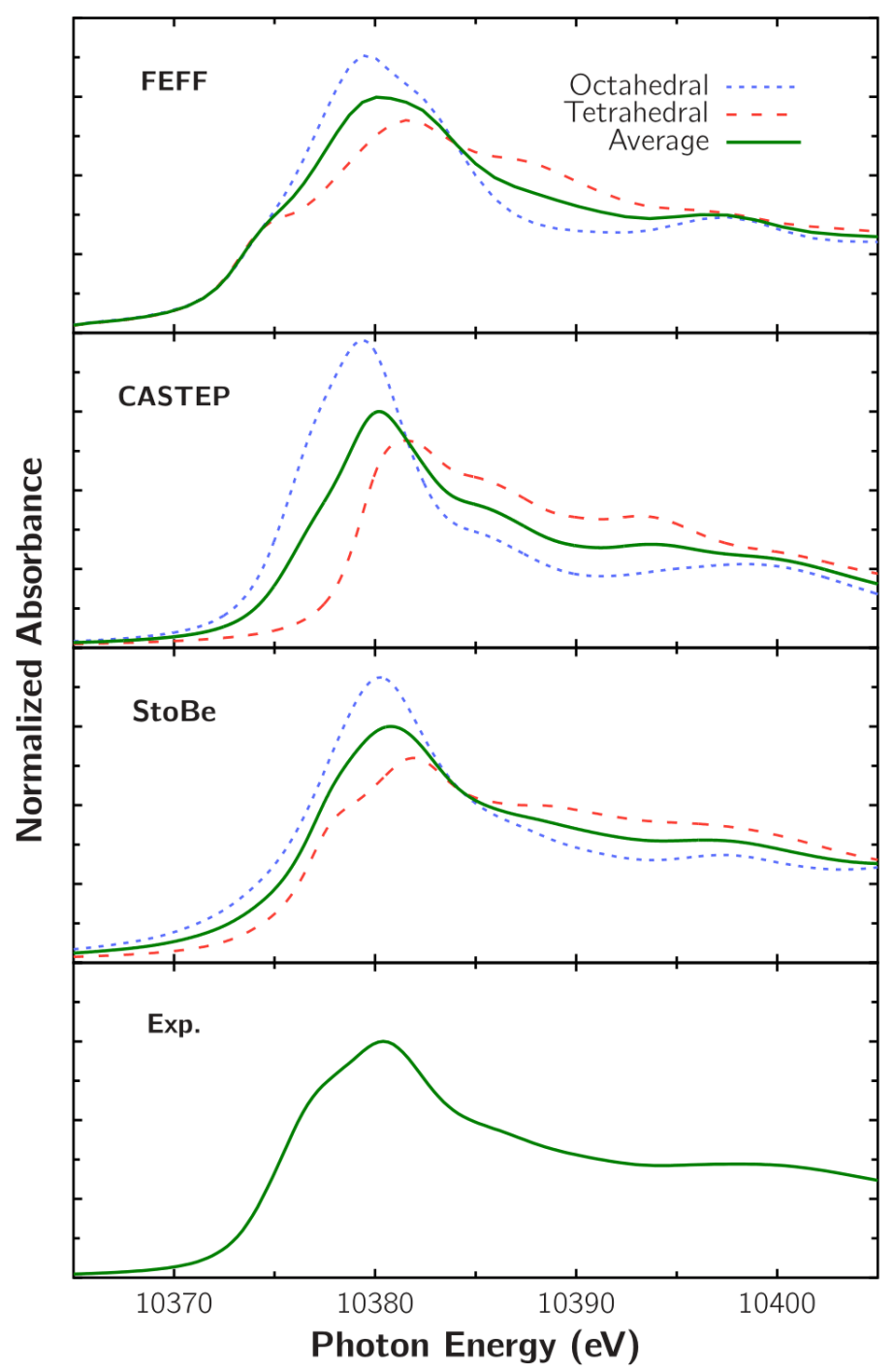

Figure 4: Comparison of the experimental Ga K-edge XANES of $\beta-\mathrm{Ga}_{2} \mathrm{O}_{3}$ with spectra simulated using FEFF, CASTEP and StoBe. The theoretical results show the individual simulations for the octahedral and tetrahedral Ga sites (dotted blue and dashed red lines, respectively), as well as their average (solid green lines). The site contributions are weighted equally in the average, according to the experimental structure. The CASTEP-computed components are shifted to align with the maxima computed by FEFF. 


\section{Conclusions}

In summary, first principles simulations of the XANES for well-defined Ga(III)containing materials with known structures provide chemical insight into the large variability reported in their spectra. Comparison of the results using three different theoretical methods shows that their accuracy varies with the local environment, thus simulation results must be interpreted with caution. The large differences in edge energies for various $\mathrm{Ga}(\mathrm{III})$-containing materials are reproduced, confirming that the XANES cannot be used as a simple fingerprint of the Ga oxidation state. Several descriptors, including the coordination number and symmetry of the local ligand environment, as well as the metal-ligand bond distances, correlate with spectral features because of ligand effects on the core ionization energy and the valence state energy.

The roles of such descriptors in predicting XANES features will be especially important in guiding the construction of models for active sites and reaction pathways in Ga-containing heterogeneous catalysts, whose structures are generally not well-known. We anticipate that using descriptors to interpret the spectra will be a more reliable approach than the common practice of remarking on the resemblance to the experimental XANES of reference compounds, such as the assignment of $\mathrm{Ga}(\mathrm{I})$ features by comparison to mixed-valent $\mathrm{Ga}(\mathrm{I}) \mathrm{Ga}(\mathrm{III}) \mathrm{Cl}_{4} \cdot{ }^{10}$

This study also highlights a critical need for a similar analysis of Ga(I) XANES, to identify descriptors that can distinguish between $\mathrm{Ga}(\mathrm{I})$ and $\mathrm{Ga}(\mathrm{III})$ sites that may be present in heterogeneous catalysts. We anticipate that such descriptors will be powerful inputs in data science and machine learning approaches, which show promise as computationally efficient ways to simulate experimental spectra. ${ }^{40-44}$ 


\section{Acknowledgements}

The CASTEP simulation work was funded primarily by the Catalysis Science program of the U.S. Department of Energy, Office of Basic Energy Sciences, Division of Chemical Sciences, Biosciences and Geosciences, under award number DE-SC0014560. The resources of the Center for Institutional Research Computing at Washington State University used in this researcher were partly funded by Washington State's Joint Center for Deployment and Research in Earth Abundant Materials (JCDREAM). StoBe and FEFF simulations were conducted using resources of the National Energy Research Scientific Computing Center (NERSC), a U.S. Department of Energy Office of Science User Facility operated under contract no. DE-AC02-05CH11231. PNNL is a multi-program national laboratory operated for the U.S. DOE by Battelle. The experimental work was supported by the U.S. Department of Energy, Office of Science, Division of Basic Energy Sciences, under the Catalysis Science Initiative (DE-FG-02-03ER15467). Use of the Stanford Synchrotron Radiation Lightsource, SLAC National Accelerator Laboratory, was supported by the U.S. Department of Energy, Office of Science, Office of Basic Energy Sciences, under Contract DE-AC02-76SF00515. Co-ACCESS is supported by the U.S. Department of Energy, Office of Basic Energy Sciences, Chemical Sciences, Geosciences and Biosciences Division. The authors thank Adam S. Hock for discussions and sharing experimental XANES data. The authors thank Adam S. Hoffman, Ariel Whitten, Charles E. Umhey and Katelyn L. McMurray for fruitful discussions.

\section{Supporting Information}

The Supporting Information is available free of charge at https://pubs.acs.org/doi/xxx/xxx 
Quantitative comparison between experimental and simulated spectra (Table S1, Figure S10), structures used for the computation of the XANES (Figures S1-S9), functional dependence of the computed XANES (Figures S11-S13), dependence of the computational spectra on Ph substitution, comparison between computed and experimental XANES for $\mathrm{GaMe}_{3}$ (Figure S15), excited density of states for selected Ga complexes, with associated orbital visualizations (Figures S16-S18), crystallographic data for the DFT-based structures.

\section{References}

(1) Sattler, J.J.H.B.; Ruiz-Martinez, J.; Santillan-Jimenez, E.; Weckhuysen, B.M. Catalytic Dehydrogenation of Light Alkanes on Metals and Metal Oxides. Chem. Rev. 2014, 114, 1061310653.

(2) Gosling, C.D.; Hamm, D.A., Process for the production of benzene from light hydrocarbons. 1993.

(3) Meitzner, G.D.; Iglesia, E.; Baumgartner, J.E.; Huang, E.S. The Chemical State of Gallium in Working Alkane Dehydrocyclodimerization Catalysts. In situ Gallium K-Edge X-Ray Absorption Spectroscopy. J. Catal. 1993, 140, 209-225.

(4) Phadke, N.M.; Van der Mynsbrugge, J.; Mansoor, E.; Getsoian, A.B.; Head-Gordon, M.; Bell, A.T. Characterization of Isolated $\mathrm{Ga}^{3+}$ Cations in Ga/H-MFI Prepared by Vapor-Phase Exchange of H-MFI Zeolite with $\mathrm{GaCl}_{3}$. ACS Catal. 2018, 8, 6106-6126.

(5) Hensen, E.J.M.; Pidko, E.A.; Rane, N.; van Santen, R.A., Modification of Brønsted Acidity of Zeolites by $\mathrm{Ga}^{+}, \mathrm{GaO}^{+}$and $\mathrm{AlO}^{+}$: Comparison for Alkane Activation, in Studies in Surface Science and Catalysis, R. Xu, Z. Gao, J. Chen, and W. Yan, Editors. 2007, Elsevier. p. 11821189.

(6) Hensen, E.J.M.; García-Sánchez, M.; Rane, N.; Magusin, P.C.M.M.; Liu, P.-H.; Chao, K.-J.; van Santen, R.A. In situ Ga K Edge XANES Study of the Activation of Ga/ZSM-5 Prepared by Chemical Vapor Deposition of Trimethylgallium. Catal. Lett. 2005, 101, 79-85.

(7) Zhidomirov, G.M.; Shubin, A.A.; Milov, M.A.; Kazansky, V.B.; van Santen, R.A.; Hensen, E.J.M. Cluster Model DFT Study of CO Adsorption to Gallium Ions in Ga/HZSM-5. J. Phys. Chem. C 2008, 112, 3321-3326.

(8) Kuz'min, I.V.; Zhidomirov, G.M.; Solkan, V.N.; Kazanskii, V.B. Quantum Chemical Calculation of the Catalytic Reaction of Ethane Dehydrogenation on Gallium OxideHydroxide Binuclear Clusters in Oxidized GaO/ZSM-5 Zeolite. Kinet. Catal. 2009, 50, 752.

(9) Hensen, E.J.M.; Pidko, E.A.; Rane, N.; van Santen, R.A. Water-Promoted Hydrocarbon Activation Catalyzed by Binuclear Gallium Sites in ZSM-5 Zeolite. Angew. Chem. Int. Ed. Engl. 2007, 46, 7273-7276. 
(10) Schreiber, M.W.; Plaisance, C.P.; Baumgärtl, M.; Reuter, K.; Jentys, A.; Bermejo-Deval, R.; Lercher, J.A. Lewis-Brønsted Acid Pairs in Ga/H-ZSM-5 to Catalyze Dehydrogenation of Light Alkanes. J. Am. Chem. Soc. 2018, 140, 4849-4859.

(11) Pidko, E.A.; Kazansky, V.B.; Hensen, E.J.M.; van Santen, R.A. A Comprehensive Density Functional Theory Study of Ethane Dehydrogenation Over Reduced Extra-Framework Gallium Species in ZSM-5 Zeolite. J. Catal. 2006, 240, 73-84.

(12) Searles, K.; Siddiqi, G.; Safonova, O.V.; Copéret, C. Silica-Supported Isolated Gallium Sites as Highly Active, Selective and Stable Propane Dehydrogenation Catalysts. Chem. Sci. 2017, $8,2661-2666$.

(13) Cybulskis, V.J.; Pradhan, S.U.; Lovón-Quintana, J.J.; Hock, A.S.; Hu, B.; Zhang, G.; Delgass, W.N.; Ribeiro, F.H.; Miller, J.T. The Nature of the Isolated Gallium Active Center for Propane Dehydrogenation on $\mathrm{Ga} / \mathrm{SiO}_{2}$. Catal. Lett. 2017, 147, 1252-1262.

(14) Szeto, K.C.; Jones, Z.R.; Merle, N.; Rios, C.; Gallo, A.; Le Quemener, F.; Delevoye, L.; Gauvin, R.M.; Scott, S.L.; Taoufik, M. A Strong Support Effect in Selective Propane Dehydrogenation Catalyzed by $\mathrm{Ga}(\mathrm{i}-\mathrm{Bu})_{3}$ Grafted onto $\gamma$-Alumina and Silica. ACS Catal. 2018, 8, 7566-7577.

(15) Szeto, K.C.; Gallo, A.; Hernández-Morejudo, S.; Olsbye, U.; De Mallmann, A.; Lefebvre, F.; Gauvin, R.M.; Delevoye, L.; Scott, S.L.; Taoufik, M. Selective Grafting of $\mathrm{Ga}(\mathrm{i}-\mathrm{Bu})_{3}$ on the Silanols of Mesoporous H-ZSM-5 by Surface Organometallic Chemistry. J. Phys. Chem. C 2015, 119, 26611-26619.

(16) Getsoian, A.B.; Das, U.; Camacho-Bunquin, J.; Zhang, G.; Gallagher, J.R.; Hu, B.; Cheah, S.; Schaidle, J.A.; Ruddy, D.A.; Hensley, J.E., et al. Organometallic Model Complexes Elucidate the Active Gallium Species in Alkane Dehydrogenation Catalysts Based on Ligand Effects in Ga K-edge XANES. Catal. Sci. Technol. 2016, 6, 6339-6353.

(17) Nishi, K.; Shimizu, K.-i.; Takamatsu, M.; Yoshida, H.; Satsuma, A.; Tanaka, T.; Yoshida, S.; Hattori, T. Deconvolution Analysis of Ga K-Edge XANES for Quantification of Gallium Coordinations in Oxide Environments. J. Phys. Chem. B 1998, 102, 10190-10195.

(18) Rehr, J.J.; Kas, J.J.; Prange, M.P.; Sorini, A.P.; Takimoto, Y.; Vila, F. Ab Initio Theory and Calculations of X-Ray Spectra. C. R. Phys. 2009, 10, 548-559.

(19) Rehr, J.J.; Kas, J.J.; Vila, F.D.; Prange, M.P.; Jorissen, K. Parameter-Free Calculations of XRay Spectra With FEFF9. Phys. Chem. Chem. Phys. 2010, 12, 5503-5513.

(20) Gao, S.-P.; Pickard, C.J.; Payne, M.C.; Zhu, J.; Yuan, J. Theory of Core-Hole Effects in $1 s$ Core-Level Spectroscopy of the First-Row Elements. Phys. Rev. B 2008, 77, 115122.

(21) Triguero, L.; Pettersson, L.G.M.; Ågren, H. Calculations of X-ray Emission Spectra of Molecules and Surface Adsorbates by Means of Density Functional Theory. J. Phys. Chem. A 1998, 102, 10599-10607.

(22) Clark, S.J.; Segall, M.D.; Pickard, C.J.; Hasnip, P.J.; Probert, M.I.J.; Refson, K.; Payne, M.C. First Principles Methods Using CASTEP. Z. Kristallogr. Cryst. Mater. 2005, 220, 567.

(23) Perdew, J.P.; Burke, K.; Ernzerhof, M. Generalized Gradient Approximation Made Simple. Phys. Rev. Lett. 1996, 77, 3865-3868.

(24) Geller, S. Crystal Structure of $\beta-\mathrm{Ga}_{2} \mathrm{O}_{3}$. J. Chem. Phys. 1960, 33, 676.

(25) BOVIA Materials Studio 2016 (16.1.0.21). 2015, Dassault Systèmes: San Diego.

(26) Åhman, J.; Svensson, G.; Albertsson, J. A Reinvestigation of $\beta$-Gallium Oxide. Acta Crystallogr. C Struct. Chem. 1996, 52, 1336-1338.

(27) Becke, A.D. Density-Functional Exchange-Energy Approximation With Correct Asymptotic Behavior. Phys. Rev. A 1988, 38, 3098-3100. 
(28) Perdew, J.P.; Yue, W. Accurate and Simple Density Functional for the Electronic Exchange Energy: Generalized Gradient Approximation. Phys. Rev. B 1986, 33, 8800-8802.

(29) Bare, S.R.; Vila, F.D.; Charochak, M.E.; Prabhakar, S.; Bradley, W.J.; Jaye, C.; Fischer, D.A.; Hayashi, S.T.; Bradley, S.A.; Rehr, J.J. Characterization of Coke on a Pt-Re/ $\gamma-\mathrm{Al}_{2} \mathrm{O}_{3} \mathrm{Re}-$ Forming Catalyst: Experimental and Theoretical Study. ACS Catal. 2017, 7, 1452-1461.

(30) Ravel, B.; Newville, M. ATHENA, ARTEMIS, HEPHAESTUS: Data Analysis for X-ray Absorption Spectroscopy Using IFEFFIT. J. Synchrotron Radiat. 2005, 12, 537-541.

(31) Mizoguchi, T.; Tanaka, I.; Gao, S.-P.; Pickard, C.J. First-Principles Calculation of Spectral Features, Chemical Shift and Absolute Threshold of ELNES and XANES Using a Plane Wave Pseudopotential Method. J. Phys. Condens. Matter 2009, 21, 104204.

(32) Slater, J.C. Wave Functions in a Periodic Potential. Phys. Rev. 1937, 51, 846-851.

(33) Zhang, R.; McEwen, J.-S. Local Environment Sensitivity of the Cu K-Edge XANES Features in Cu-SSZ-13: Analysis from First-Principles. J. Phys. Chem. Lett. 2018, 9, 3035-3042.

(34) van Bokhoven, J.A. In-situ Al K-edge Spectroscopy on Zeolites: Instrumentation, Datainterpretation and Catalytic Consequences. Phys. Scr. 2003, T115, 76-79.

(35) Stepanic, O.M.; Ward, J.; Penner-Hahn, J.E.; Deb, A.; Bergmann, U.; DeBeer, S. Probing a Silent Metal: A Combined X - ray Absorption and Emission Spectroscopic Study of Biologically Relevant Zinc Complexes. Inorg. Chem. 2020, 59, 13551-13560.

(36) Notestein, J.M.; Andrini, L.R.; Kalchenko, V.I.; Requejo, F.G.; Katz, A.; Iglesia, E. Structural Assessment and Catalytic Consequences of the Oxygen Coordination Environment in Grafted Ti-Calixarenes. J. Am. Chem. Soc. 2007, 129, 1122-1131.

(37) Bordiga, S.; Bonino, F.; Damin, A.; Lamberti, C. Reactivity of Ti(IV) Species Hosted in TS1 Towards $\mathrm{H}_{2} \mathrm{O}_{2}-\mathrm{H}_{2} \mathrm{O}$ Solutions Investigated by $\mathrm{Ab}$ Initio Cluster and Periodic Approaches Combined with Experimental XANES and EXAFS Data: A Review and New Highlights. Phys. Chem. Chem. Phys. 2007, 9, 4854-4878.

(38) Mo, S.-D.; Ching, W.Y. X-ray Absorption Near-Edge Structure in Alpha-Quartz and Stishovite: Ab Initio Calculation With Core-Hole Interaction. Appl. Phys. Lett. 2001, 78, 3809.

(39) Reed, A.E.; Weinhold, F. Natural Localized Molecular Orbitals. J. Chem. Phys. 1985, 83, 1736-1740.

(40) Gao, P.; Zhang, J.; Peng, Q.; Zhang, J.; Glezakou, V.-A. General Protocol for the Accurate Prediction of Molecular ${ }^{13} \mathrm{C} /{ }^{1} \mathrm{H}$ NMR Chemical Shifts via Machine Learning Augmented DFT. J. Chem. Inf. Model. 2020, 60, 3746-3754.

(41) Carbone, M.R.; Topsakal, M.; Lu, D.; Yoo, S. Machine-Learning X-Ray Absorption Spectra to Quantitative Accuracy. Phys. Rev. Lett. 2020, 124, 156401.

(42) Timoshenko, J.; Frenkel, A.I. "Inverting" X-ray Absorption Spectra of Catalysts by Machine Learning in Search for Activity Descriptors. ACS Catal. 2019, 9, 10192-10211.

(43) Mathew, K.; Zheng, C.; Winston, D.; Chen, C.; Dozier, A.; Rehr, J.J.; Ong, S.P.; Persson, K.A. Data Descriptor: High-throughput Computational X-ray Absorption Spectroscopy. Sci. Data 2018, 5, 180151

(44) Timoshenko, J.; Jeon, H.S.; Sinev, I.; Haase, F.T.; Herzog, A.; Cuenya, B.R. Linking the Evolution of Catalytic Properties and Structural Changes in Copper-Zinc Nanocatalysts Using Operando EXAFS and Neural-Networks. Chem. Sci. 2020, 11, 3727. 